\section{Ape import cuts hit research}

\section{San Francisco}

THE eight-month-old restriction on the import of some of the most important research primates has tripled the price of the animals and seriously curtailed primate research in the United States, according to researchers.

The shortage of research primates is growing as primate importers across the United States come into line with the strict quarantine requirements demanded by the federal Centers for Disease Control (CDC) earlier this year after the discovery of a suspicious filovirus that was making ill and killing imported monkeys and apparently infecting handlers as well.

Researchers says they must now endure long delays to get the primates they need for research. "There's no question it's had a definite negative impact on research and the whole supply line of research animals into the United States", says Jeff Roberts, assistant director of the California Primate Research Center at the University of California at Davis.

Many research projects that rely on imported monkeys and apes have been halved, he estimates, because the required animals are either not available or are now prohibitively expensive. The cost of one cynomolgus macaque, for example, has risen from $\$ 400$ to nearly $\$ 1,200$ in recent months.

The primatologists' pinch is the result of a year of nervous manoeuvring and rulewriting. Last autumn, in several shipments of monkeys from Asia to the United States, a filovirus was identified that appeared quite similar to Ebola, a virus that caused large outbreaks of often-fatal human disease in Africa in the 1970s. When testing of humans who had had contact with the imported animals revealed several positive antibody tests, the CDC took action.

In March they issued a mandatory series of guidelines on quarantine and handling of primates. The CDC also told US primate centres that they would begin unannounced site inspections. As a result, many primate importers, including three of the country's largest centres, which together account for more than 80 per cent of all US imports, were closed down last spring.

Meanwhile, the New York State Health Department added an additional layer of safeguards by declaring that it would permit cynomolgus, rhesus or African green monkeys to enter the state only if they had been quarantined in their country of origin for 60 days and had tested negative for the filovirus. Even so, animals entering the United States through New York, as do most of those imported into the country, must be requarantined and retested after importation. Importers must also make special arrangements with wary airlines to ensure that employees are not exposed to the virus during transport.

Despite the new restrictions, the flow of primates into US institutions is at last beginning to pick up again. In April, the CDC announced that special permits would be made available for the importation of cynomolgus. African green and rhesus monkeys if importers met certain requirements. Since then, primate importers, university laboratories and zoos around the nation have been scrambling to remodel quarantine facilities and to develop stringent new procedures for disinfecting facilities, handling animals and waste and routinely testing animals and human handlers for the filovirus. In recent weeks, several importers have been granted special permits and a handful have been given rights to unlimited importation for a 180 -day period. Many others are in the process of applying to the CDC for reinstatement.

In California, where 20 of the state's former 36 primate importers are under review for new permits, still another layer of bureaucracy and another round of quarantine and filovirus testing is needed for imported primates. For 20 years, the state has required a 30 -day quarantine for incoming primates, even those coming from other states. That policy remains in place, with recent upgrades, despite its redundancy with the federal requirements.

Despite the problems caused by shortages and the fact that none of the human infections have so far resulted in any symptoms, the "need for extreme caution" remains, according to the CDC's Brian Mahy, who directs the division studying the filovirus infection.

The key question now, he believes, is whether the virus survives after infection in animals that are not killed by the pathogen. The existing evidence is that the virus does not survive long-term in the body, he says.

Those who use primates agree that it is crucial to protect their employees and their animals from the virus, but the CDC's response raises questions for many. Importers point out that the United States is the only importing nation to tighten regulations because of the filovirus, and no health problems have been reported in other countries. Meanwhile, the delays mean a sharp decline in the US breeding stocks of primates that help to sustain research institutions such as the seven regional primate centres sponsored by the National Institutes of Health. Zoos are also worried, because additional delays may begin to hurt their cooperative programmes to breed endangered species.

Elizabeth Schaefer at the zoo?

\section{London}

AN antelope from London Zoo, never fed the animal feed thought to harbour the infective agent of bovine spongiform encephalopathy (BSE), is being examined to determine if it died of the disease. If the 18month-old kudu, which suffered from an unspecified neurological complaint, is found to have had a spongiform encephalopathy, fears that BSE can be passed down from mother to offspring will be reawakened: the animal's mother died of a spongiform encephalopathy in 1989 (see Nature 344, 183; 1990).

Maternal transmission occurs in sheep infected with scrapie, which is thought to be caused by the same as-yet-unidentified agent. More than 300 calves of BSEinfected cows are being studied by agriculture ministry epidemiologists, but none of the herd, now more than two years old, have yet developed the disease. Nevertheless, maternal transmission in an antelope would increase pressure for a breeding ban from the offspring of BSE cases.

The new scare comes as the government announced an inquiry into the animal feed industry, and banned the splitting of cow heads in abattoirs, to prevent aerosols of possibly infective brain tissue being sprayed over meat for human consumption.

A diagnosis for the new antelope case is expected within the next few weeks, after pathologists at the Central Veterinary Laboratory have examined the animal's brain. But James Kirkwood, senior veterinary officer at London Zoo, says that he "wouldn't be surprised if it turns out be be negative". Several suspected cases of maternally transmitted BSE in cattle have proved to be false alarms. Peter Aldhous AIDS

\section{Soviet television to raise AIDS funds}

\section{London}

SOVIET television is planning an all-day broadcast on World AIDS day, 1 December, to raise money for AIDS research, modelled on the charity fundraising 'telethons' that have become a feature of British television in recent years.

This year's World AIDS day, coordinated by the World Health Organization (WHO) to highlight efforts to fight the worldwide pandemic, takes the theme of 'Women and AIDS'. WHO estimates that about 200,000 women will develop the disease within the next year. Heterosexual transmission of the disease to women is an increasing problem -27 per cent of European women with AIDS are thought to have been infected through sexual intercourse with a HIV-positive man.

Peter Aldhous 